\title{
A small but important step to enhance groundwater research in China
}

Sponsored by the Chinese Academy of Sciences (CAS) and the National Natural Science Foundation of China, Chinese Science Bulletin (CSB) is one of the well-known comprehensive academic journals of wide impacts in the field of natural sciences in China. Groundwater research has become increasingly important due to the long-term and high-speed social and economic development of our country. Despite these, only a few papers in the field of groundwater hydrogeology have been published in this journal, which is very unproportional to the importance of the subject of groundwater hydrogeology in China.

In order to facilitate the advance of groundwater hydrogeology, the Department of Earth Science, National Natural Science Foundation of China, suggested to several groundwater hydrogeologists in China University of Geosciences-Beijing to consult with the Editorial Office of CSB about the possibility of having a special topic on "Groundwater". The idea of such a special topic was strongly supported by the CSB editors and the CSB Editorial Office.

With their supports to the plan for publishing a special topic of "Groundwater", we sent invitation letters to 24 selected wellknown groundwater hydrogeologists in our country to solicit papers for this special topic. Our invitation was warmly responded by 10 of them and 11 papers were submitted. Each of these paper was then peer-reviewed by three reviewers, including at least one overseas reviewer. Based on the review comments, finally 7 of 11 papers were accepted for publication in this special topic.

These papers include analytical and experimental studies of delayed groundwater drainage from an aquitard due to sudden head decrease in adjacent confined aquifer [1]; suitability assessment of deep groundwater for drinking, irrigation and industrial purposes in Jiaozuo City [2]; groundwater circulation in an arid transitional zone linking oasis, desert and river and its dominant impact on local water quality and vegetation [3]; spatial-temporal evolutions of groundwater arsenic along the flow path in the Hetao basin, Inner Mongolia [4]; impacts of the Wenchuan earthquake in 2008 on the observed earth tides in the Three Gorges well network and on aquifer parameters [5]; review papers of the uncertainty analysis of groundwater numerical simulation [6] and tidal contribution to submarine groundwater discharges [7].

I think that it is very important for all the groundwater hydrogeologists to strengthen collaboration and support each other in all aspects of the research work of the groundwater hydrogeology community. Only by enhancing collaboration and multidisciplinary research within the community and beyond, can our community grow stronger and catch up with other alreadystrong research communities such as petroleum geology, structural geology, and engineering geology. The publication of this groundwater special topic took a small but important step in this direction. I hope that, with the collective efforts of all members of the groundwater research community, the studies in groundwater hydrogeology in China will make great and quick progress in the near future.

1 Zhou Z F, Guo Q N, Dou Z. Delayed drainage of aquitard in response to sudden change in groundwater level in adjacent confined aquifer: Analytical and experimental studies. Chin Sci Bull, 2013, 58: 3060-3069

2 Shi J S, Ma R, Liu J C, et al. Suitability assessment of deep groundwater for drinking, irrigation and industrial purpose in Jiaozuo City (Henan Province, North China). Chin Sci Bull, 2013, 58: 3098-3110

3 Huang T M, Pang Z H, Chen Y N, et al. Groundwater circulation relative to water quality and vegetation in an arid transitional zone linking oasis, desert and river. Chin Sci Bull, 2013, 58: 3088-3097

4 Guo H M, Zhang Y, Jia Y F, et al. Spatial and temporal evolutions of groundwater arsenic approximately along the flow path in the Hetao basin, Inner Mongolia. Chin Sci Bull, 2013, 58: 3070-3079

5 Shi Z M, Wang G C, Liu C L, et al. Coseismic response of groundwater level in the Three Gorges well network and its relationship to aquifer parameters. Chin Sci Bull, 2013, 58: 3080-3087

6 Wu J C, Zeng X K. Review of the uncertainty analysis of groundwater numerical simulation. Chin Sci Bull, 2013, 58: 3044-3052

7 Li H L, Jiao J J. Quantifying tidal contribution to submarine groundwater discharge: A review. Chin Sci Bull, 2013, 58: 3053-3059

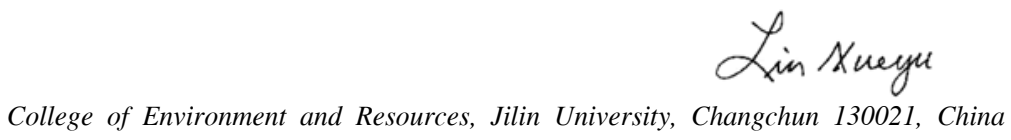

Open Access This article is distributed under the terms of the Creative Commons Attribution License which permits any use, distribution, and reproduction in any medium, provided the original author(s) and source are credited. 